\title{
Michèle Bokobza-Kahan, Témoigner des miracles au siècle des Lumières. Récits et discours de Saint-Médard
}

\section{Vittorio Fortunati}

\section{(2) OpenEdition}

1 Journals

\section{Edizione digitale}

URL: http://journals.openedition.org/studifrancesi/5329

DOI: $10.4000 /$ studifrancesi.5329

ISSN: 2421-5856

\section{Editore}

Rosenberg \& Sellier

\section{Edizione cartacea}

Data di pubblicazione: 1 dicembre 2016

Paginazione: $527-528$

ISSN: 0039-2944

\section{Notizia bibliografica digitale}

Vittorio Fortunati, « Michèle Bokobza-Kahan, Témoigner des miracles au siècle des Lumières. Récits et discours de Saint-Médard », Studi Francesi [Online], 180 (LX | III) | 2016, online dal 01 janvier 2017, consultato il 18 septembre 2020. URL : http://journals.openedition.org/studifrancesi/5329; DOI : https://doi.org/10.4000/studifrancesi.5329

Questo documento è stato generato automaticamente il 18 settembre 2020.

\section{(c) (1)}

Studi Francesi è distribuita con Licenza Creative Commons Attribuzione - Non commerciale - Non opere derivate 4.0 Internazionale. 


\title{
Michèle Bokobza-Kahan, Témoigner des miracles au siècle des Lumières. Récits et discours de Saint-Médard
}

\author{
Vittorio Fortunati
}

\section{NOTIZIA}

MICHÈLE воковZA-KAнAN, Témoigner des miracles au siècle des Lumières. Récits et discours de Saint-Médard, Paris, Classiques Garnier, 2015, 372 pp.

1 Nei primi decenni del XVIII secolo, dopo la condanna papale sancita dalla bolla Unigenitus (1713) e la distruzione, voluta da Luigi XIV, del monastero di Port-Royal, il giansenismo sopravviveva in Francia in una condizione di semi-clandestinità, soprattutto nell'ambito del basso clero. $\mathrm{Fu}$ su questo sfondo che si verificarono $\mathrm{i}$ cosiddetti miracoli di Saint-Médard, una serie di guarigioni apparentemente inspiegabili, avvenute negli anni tra il 1727 e il 1732 e attribuite al diacono giansenista François de Pâris, sepolto nel cimitero attiguo all'omonima chiesa parigina. Le autorità ecclesiastiche si mostrarono fin dall'inizio (e rimasero) molto scettiche nei riguardi del fenomeno; i primi philosophes videro nell'accorrere della folla a Saint-Médard una delle tante manifestazioni della credulità popolare. Resta il fatto che, tra il 1732 e il 1735, furono raccolte e pubblicate in dieci volumi le testimonianze relative a più di un centinaio di eventi miracolosi. È questo l'imponente corpus preso in esame da Michèle Bokobza Kahan, francesista dell'Università di Tel-Aviv e autrice d'importanti saggi sulle tematiche relative alla follia e alla devianza nel secolo dei Lumi, tra i quali ci piace ricordare soprattutto i due volumi Libertinage et folie dans le roman du $\mathrm{xVIII}^{\mathrm{e}}$ siècle, del 2000, e Dulaurens et son œuvre. Un auteur marginal au XVIII ${ }^{\mathrm{e}}$ siècle: déviances discursives et bigarrures philosophiques, del 2010.

2 Il presente volume si apre con un capitolo introduttivo («Le témoignage de miracle: les avatars d'un genre») che inserisce le testimonianze relative ai miracoli di Saint-Médard 
nell'evoluzione del genere d'appartenenza. Mentre nel Medioevo i testimoni tendevano a sottolineare l'aspetto prodigioso degli eventi, visti come una prova dell'onnipotenza divina, con l'età moderna (e le testimonianze di Saint-Médard non fanno eccezione) si tende piuttosto a fornire prove dell'attendibilità dei testimoni: sotto questo aspetto, anche un genere della letteratura religiosa rivela la crescente influenza del pensiero scientifico moderno. Le tre parti in cui è suddivisa la trattazione affrontano il problema della credibilità da diverse prospettive. La prima parte («Enjeux éditoriaux») mostra gli espedienti mediante i quali gli editori cercavano di conferire maggiore autorevolezza alle testimonianze che pubblicavano: anche il grande formato dei volumi era utile allo scopo. Nella seconda parte («L'ethos testimonial») vengono descritte le principali tipologie di testimoni: i miracolati, i loro portavoce, i testimoni oculari dei fenomeni. Oggetto della sezione successiva («Les mots pour témoigner») sono le strategie adottate dai testimoni per risultare convincenti: la descrizione particolareggiata delle sofferenze patite, l'elenco dei tentativi inutili di cura, le sensazioni che hanno preceduto e accompagnato la guarigione. La quarta e ultima parte («Témoignage et narration») offre una riflessione sulla testimonianza come genere letterario, mostrando che in essa, al pari di quanto avviene nel romanzo, il narratore cerca di suscitare e tenere vive la curiosità e la suspense del lettore. Inoltre, la persona del testimone, con le sue sensazioni, le sue esperienze, il suo modo di interpretare i fatti, assume sempre di più un ruolo centrale: da questo punto di vista, le testimonianze dei miracoli si apparentano ai "generi dell'Io" (memorie, romanzi in prima persona,...) che vedono la loro fioritura proprio nel Settecento. Il saggio di M. Bokobza-Kahan, pur avendo come oggetto un genere decisamente "settoriale", ci fornisce quindi uno scorcio inedito sulla situazione storico-culturale agli albori del secolo dei Lumi. 